\title{
Critically III Children Admitted into the Paediatric Emergency Unit of a Tertiary Hospital in a Developing Country and the Causes of Delayed Presentation
}

\author{
Labaeka Adeyemi Adeyinka \\ Department of Paediatrics, University College Hospital, Ibadan, Nigeria
}

Email address:

yemilabaeka2@gmail.com

\section{To cite this article:}

Labaeka Adeyemi Adeyinka. Critically Ill Children Admitted into the Paediatric Emergency Unit of a Tertiary Hospital in a Developing Country and the Causes of Delayed Presentation. Science Journal of Clinical Medicine. Vol. 9, No. 4, 2020, pp. 91-94.

doi: $10.11648 /$ j.sjcm. 20200904.12

Received: October 14, 2020; Accepted: October 28, 2020; Published: November 11, 2020

\begin{abstract}
Decades of advancement in health care delivery and clinical practice may have massively impacted the efficiency of health delivery and patient outcome in high-income countries, but its effect is still minimal in the low-income countries who are still dealing with poorly equipped and inadequate health facilities low insurance coverage and poor education. This study set out to evaluate the clinical profiles of critically ill admitted into the paediatric emergency unit and causes delay presentation. A prospective review of children admitted into the children emergency room between January 2018 to December 2019 . A total of 8087 emergency room visits were attended to over the two years out of which 4039 were admitted. The majority of participants $(63.5 \%)$ are less than 5 years, there was a male to female ratio of $1.6: 1$ and $1458(36.1 \%)$ had emergency signs necessitating resuscitation at presentation. $74 \%$ of participants have been self-medicated by parent/caregiver before presenting in the hospital (50\% antibiotics, 44\% antimalaria). The most frequent symptoms include fever, vomiting, breathlessness and seizures, majority $(73 \%)$ of those with emergency sign presented 48 hours after onset of symptoms and the major reason for the delay was the fear of the cost of treatment. Children that had significant odd of dying include those that: were self-medicated, had emergency signs and under- 5 children. The high dependence of out-of-pocket financing in Nigeria health care system remains a major cause of delayed presentation among critically ill children. There is an urgent need for the government to improve on the universal health coverage by improving the number of the population with health insurance coverage.
\end{abstract}

Keywords: Critically Ill Child, ETAT, Emergency Signs, Delay Presentation, Emergency Room

\section{Introduction}

Despite massive technological breakthrough and advancement in medical practice in the last three decades, the total number of death among children and young adolescents remain at a staggering figure of 6.7 million in 2018, with infant mortality accounting for about $85 \%$ of the deaths [1]. The majority (52\%) of these deaths occurs in Sub-Saharan Africa, where the risk of children dying if 16 times higher than high-income countries [1]. In developing countries, the problem high mortality rate in children has been associated with late presentation to the hospital, poor accessibility to health facilities, non-availability of trained health workers, inadequate drugs and equipment, non-standardized treatment guidelines, severe malnutrition, poor and ineffective health insurance coverage and low level of education [2]. Majority of deaths of children in the hospital usually occurs in the first 24 hours of admission, most of which are preventable if the sick child was promptly identified and appropriate treatment started immediately upon arrival in the hospital. To facilitate triaging of sick children presenting to the hospital, the World Health (WHO) developed a simplified triaging tool from Advanced Paediatric Life Support guideline, known as Emergency Triage, Assessment and Treatment (ETAT). This tool helps in early identification of children with lifethreatening conditions that are prevalent in the developing countries [3-5].

This study aims to evaluate the clinical and epidemiological data of children admitted into children emergency unit to identification of the spectrum and severity 
of illness and also causes of delays in late presentation. This will help to design an effective paediatric emergency care in a resource-limited setting.

\section{Materials and Methods}

The study was prospective, including all children that presented to the paediatric emergency unit of the University College Hospital Ibadan, Nigeria between January 2018 and December 2019. This hospital is a multi-disciplinary tertiary hospital and a referrer hospital serving the southwestern part of Nigeria and the first postgraduate training centre for general paediatrics in the country. The paediatric emergency room is 16 bedded and has an average of 4000 emergency room visits per annum and an average of 2000 admissions per annum, multiple visits were not excluded. Patient included in this study have age ranges from one month to the age of 16 years, while neonates are admitted into a separate neonatal emergency room in our hospital.

The patients' caregivers were interviewed to collect demographic data (age, gender) symptoms and its duration, history of self-medication and the medication used, number of hospitals visited before presentation and reasons for present late among those with emergency signs. The WHO ETAT score during triaging was also recorded. These outcomes of interest were entered and analysed into IBM ${ }^{\circledR}$ Statistical Package of Social Science (SPSS) version 22 results were expressed using descriptive statistics and bivariate analysis with the level of significance was set at $<0.001$.

\section{Results}

The total number of emergency room visit over the two years was 8087 , multiple visits inclusive and only $810(10 \%)$ had health insurance coverage and about 50\% (4039) these children were admitted. There was a male preponderance $(61.6 \%)$ among those admitted and about one-fifth of them are infants and those between 12-60 months are the predominant group (43.5\%). Slightly above a third of the patients $(36.1 \%)$ had emergency signs and needed resuscitation at presentation as seen in table 1 . The table also showed that more than two-third have visited one or more hospitals before presenting to the hospital. Furthermore, there is a high level of self-medication (by the caregivers) involving more than three-quarter of the study population, with half of the children already exposed to antibiotics before the presentation. About $40 \%$ have taken oral antimalarial, while $12 \%$ have used a herbal mixture. The highest odd of dying was noticed among children that were self-medicated OR $11.8(95 \% \mathrm{CI}=3.7-37.4)$, those with emergency signs OR $4.6(95 \% \mathrm{CI}=3.0-7.1)$ and those less than 5 years OR $1.5(95 \% \mathrm{CI}=1.0-2.3)$, while children without health insurance and male gender also had greater odds of dying but was not significant (Table 1).

Table 1. Demography And Outcome Of Admitted Patients.

\begin{tabular}{|c|c|c|c|c|c|}
\hline & $\begin{array}{l}\text { Frequency of cohort } \\
(n=4039)\end{array}$ & $\begin{array}{l}\text { Percentage of cohorts } \\
(\%)\end{array}$ & Death $(n=101)$ & $\begin{array}{l}\text { Percentage of all } \\
\text { death }(\%)\end{array}$ & OR $(95 \% C I)$ \\
\hline \multicolumn{6}{|l|}{ Sex } \\
\hline Male & 2488 & 61.6 & 70 & 69.3 & $1.4(0.9-2.2)$ \\
\hline female & 1551 & 38.4 & 31 & 30.7 & \\
\hline \multicolumn{6}{|l|}{ Age } \\
\hline $1-11$ months & 811 & 20.1 & 19 & 18.8 & $1.5(1.0-2.3)$ \\
\hline $12-60$ months & 1757 & 43.5 & 54 & $53.5^{*}$ & \\
\hline$>60$ months & 1466 & 36.3 & 28 & 27.7 & \\
\hline \multicolumn{6}{|l|}{ ETAT } \\
\hline Emergency signs & 1458 & 36.1 & 72 & 71.3 & $4.6(3.0-7.1)$ \\
\hline Priority signs & 2581 & 63.9 & 29 & 28.7 & \\
\hline \multicolumn{6}{|c|}{ Self-medication prior to presentation } \\
\hline Yes & 2989 & 74 & 98 & $97 *$ & $11.8(3.7-27.4)$ \\
\hline No & 1050 & 26 & 3 & 3 & \\
\hline \multicolumn{6}{|c|}{ Source of health financing } \\
\hline Out-of-pocket & 3882 & 96.4 & 100 & $99 *$ & $4.1(0.6-29.8)$ \\
\hline Health insurance & 157 & 3.9 & 1 & 1 & \\
\hline \multicolumn{6}{|c|}{ Types of drugs taken as self-medication } \\
\hline Antimalarial & 1777 & 44 & & & \\
\hline Antibiotics & 2019 & 50 & & & \\
\hline Herbal concoction & 485 & 12 & & & \\
\hline Other drugs & 162 & 4 & & & \\
\hline
\end{tabular}

$* \mathrm{P}<0.001$.

Furthermore, 2.5\% (101) of admitted patients died, mortality was higher among boys and children between 1260 months though, the latter was statistically significant, people who have been to multiple hospitals before a presentation are significantly at higher risk of dying. Although many of the patients have multiple symptoms, the most common complaint among these patients was fever which was present in about $80 \%$ of patients; other common complaints are vomiting and cough (approximately 34\% each), breathlessness and seizures in about 26 and $20 \%$ respectively. Only about $20 \%$ was admitted on account of diarrhoea as seen in table 2. 
Table 3 showed that majority of children with emergency signs presented late to our hospital, about $26.3 \%$ presented within the first 48 hours of the onset of symptoms and close to a tenth presented after two weeks. The majority (about $74.3 \%$ ) of this delayed presentation could be ascribed to the fear of cost and this alludes to the fact that about $79.4 \%$ of the caregivers pay for the health care of their ward out of pocket. Other reasons for delayed presentations as shown in table 3 are; $19.8 \%$ believed the symptoms were not severe enough to warrant taking to a tertiary hospital, while family influence and spiritual beliefs are responsible for 2 and $1.8 \%$ respectively.

Table 2. Common Complaints Among The Patients.

\begin{tabular}{lll}
\hline Complaint & Frequency & Percentage \\
\hline Fever & 3231 & 80.0 \\
Vomiting & 1374 & 34.0 \\
Cough & 1369 & 33.9 \\
Breathlessness & 1050 & 26.0 \\
Seizure & 809 & 20.0 \\
Diarrhoea & 807 & 20.0 \\
Bone pain & 567 & 14.0 \\
Body swelling & 566 & 14.0 \\
Abdominal pain & 404 & 10.0 \\
Loss of consciousness & 323 & 8.0 \\
Urinary symptoms & 320 & 7.9 \\
\hline
\end{tabular}

Table 3. Duration of symptoms and reasons for delay among children with emergency signs.

\begin{tabular}{lcl}
\hline & Frequency $\mathbf{n = 1 4 5 8}$ & Percentage \\
\hline Duration of symptoms among children with emergency signs & \\
$\leq 2$ days & 384 & 26.3 \\
3-7 days & 726 & 49.8 \\
8-14 days & 210 & 14.4 \\
$>$ 14 days & 138 & 9.5 \\
Reason for late presentation & & \\
Fear of cost & 1083 & 74.3 \\
Believed Symptoms weren't & 288 & 19.8 \\
severe enough & 29 & 2.0 \\
Family influence & 22 & 1.5 \\
Rigor of teaching hospital & 26 & 1.8 \\
Spiritual reason & 10 & 0.7 \\
Delay at source of referrer & & \\
\hline
\end{tabular}

\section{Discussion}

This study found out that about $63 \%$ of children admitted in the emergency room are under five years and predominantly male, which is similar to the age-related morbidity pattern in other parts of the country and other developing countries [6-8]. The overall mortality among admitted patient was about $2.5 \%$, this mortality rate is far lower to was is obtained from many children emergency country [6-9]. This may be because the present study only considers children in the post-neonatal age group or it could be from an improvement in the overall quality of care offered in our emergency room. The trend of mortality in our facility has been on the decrease over the last 14 years (from $10.7 \%$ in 2005 to $2.5 \%$ in this present study) and the majority of these deaths are among children that came in critically ill [10]. The burden of mortality is highest among under-5 children $(72.3 \%)$ which is similar to what has been reported by previous studies $[7,9,10]$. The high vulnerability of this group has been attributed to the relative immaturity of the cellular and hormonal immune system. There was a high prevalence $(74 \%)$ of self-medication with prescription medicine among these children, while antibiotics and antimalarial are the medications most use. Self-medication is a worldwide problem with prevalence as high as $68 \%$ in Europe, up to 81.8 and $92 \%$ in some part of Africa and Kuwait respectively $[11,12]$. Other studies from Nigeria also reported a high incidence of antibiotics, antimalarial and analgesics as most common medications involved in selfmedication [13, 14]. Uncontrolled use of antibiotics and antimalarial will promote antimicrobial resistance which will further put more strain on an already fragile health care system. The risk of multidrug resistance and the high probability of administration of inappropriate and ineffective medication may have been the reason for the high odds of death associated with self-medication.

Fever was reported as the commonest presenting complaint among children in this study, Nigeria remains one of the largest contributors to the global under 5 mortalities with the majority of the cause of death being related to infectious diseases which is similar to what has been reported in other developing countries including India, Middle East and South-east Asia [15-18].

About three-quarter of children with emergency signs presented after 2 days of symptoms and the major reason for the delayed presentation was attributed to the fear of the cost of treatment in the hospital. Nigeria is a country of about 200 million people with about 83 Million living below the country's poverty line of $\$ 381.75$ per year and a Universal Health Coverage of about 5\% [19, 20]. Health care system in Nigeria is still poorly funded and the majority of families relied on private out of pocket funding as the main source of health financing. This is the major reason why they seek a cheaper alternative (but less effective) to hospital care when this fails they end up presenting late to health facilities in critical states. Many caregivers/parents have a poor understanding of the natural progression of symptoms, inability to identify danger or warning signs and underestimation of the gravity of the symptoms, make them wait for more than $48 \mathrm{hrs}$ before presenting to the emergency room.

\section{Conclusion}

Critically ill children constitute more than a third of patients presenting to the paediatric emergency room of the University College Hospital Ibadan, Nigeria. Their conditions are further complicated by a high incidence of self-medication and delayed presentation as a result of the inadequate fund to service the out-of-pocket financing which was the predominant source of health care financing among the participants. There is an urgent need for government to improve its public financing for health by the allocation of more fund to the health budget and expand the coverage of 
universal health insurance to close to $100 \%$, this will reduce the burden of catastrophic health expenditure on this family whose income has further been impoverished by the global recession and the COVID-19 pandemic. There is also an increasing need to educate parents/caregiver on warning symptoms and disease progression.

\section{References}

[1] United Nations Inter-agency Group for Child Mortality Estimation (UNIGME). Levels \& Trends in Child Mortality: Report 2019, Estimates developed by the United Nations Inter-agency Group for Child Mortality Estimation', United Nations Children's Fund, New York 2019.

[2] G. Tamburlimi, S. DeMario, R. S. Maggi, J. N. Vilarin, S. Gore. Evaluation of guidelines for emergency triage assessment and treatment in developing countries. Arch. Dis. Child. 1999; 81: 478-82.

[3] World Health Organisation. Updated Guideline: Paediatric Emergency, Triage, Assessment and Treatment. Geneva, World Health Organisation 2016.

[4] S. Gove. Integrated management of childhood illness by outpatient health workers: technical basis and overview. Bulletin of World Health Organisation 1997; 75 (suppl 1): 7 24.

[5] S. Gove, G. Tamburlini, L. Molineux, P. Whitesell, H. Campbelle. Development and technical basis of simplified guidelines for emergency triage assessment and treatment in developing countries. Arch Dis Child 1999; 81: 473-477.

[6] M. Aminu, E. Bassey, G. Bilkisu, A. Muyideen, A. Smart, O. Sunday. Pattern of medical childhood morbidity and mortality in a new specialist hospital in Gusau, Nigeria. Ann Niger Med [Internet] 2014; 8 (1): $15 . \quad$ Available from: http://www.anmjournal.com/text.asp?2014/8/1/15/141024. [Google Scholar].

[7] O. Anyanwu, O. Ezeanosike, C. Ezeonu. Pattern and outcome of admissions at the children emergency room at the Federal Teaching Hospital Abakaliki. African J Med Heal Sci [Internet] 2014; 13 (1): 6. Available from: http://www.ajmhs.org/text.asp?2014/13/1/6/139435. [Google Scholar].

[8] N. C. Charles, A. Chuku, N. M. Anazodo. Childhood mortality in federal medical centre Umuahia, South Eastern Nigeria. Oman Med J. 2014; 29 (5): 320-324. [PMC free article] [PubMed] [Google Scholar].

[9] C. O. Enyuma, M. U. Anah, A. Pousson, G. Olorunfemi et al. Pattern of Paediatric admissions and predictors of prolonged hospital stay at the Children emergency room, University of Calabar, Nigeria. Afr Health Sci 2019; 19 (2): 1910-1923.

[10] O. O. Ayoola, A. E. Orimadegun, A. K. Akinsola, K. Osinusi. A five year review of childhood mortality at the University College Hospital Ibadan. WAJM 2005; 24 (2): 175-179.

[11] O. Ehigiator, C. C. Azodo, E. E. Ehikhamenor. Selfmedication with antibiotics among Nigerian dental students. Tan dent j. 2010; 16 (2): 48-53.

[12] S. Jain, R. Malvi, J. K. Purviya. Concept of Self-medication; a Review. International Journal of Pharmaceutical and Biological Archives. 2011; 2 (3): 831-836.

[13] U. M. Lawan, I. S. Abubakar, A. M. Jibo, A. Rufai. Pattern, awareness and perceptions of health hazards associated with self-medication among adult residents of Kano metropolis, north-western Nigeria. Indian J Community Med 2013; 38: 144-51.

[14] J. M. Olakunle, A. I. Fatima, F. O. Aliyu. Pattern of SelfMedication with Prescription Medicines Among Residents of Ilorin in North Central Nigeria. RADS J Pharm Pharm Sci. 2019; 7 (4): 191-198.

[15] T. Nolan, P. Angos, A. J. Cunha AJ et al. Quality of hospital care for seriously ill children in less-developed countries. Lancet 2001; 357: 106-10. View Article.

[16] Singhi S, Jain V, Gupta G. Pediatric emergencies at a tertiary care hospital in India. J Trop Pediatr 2003; 49: 207-11.

[17] Zaidi AK, Awasthi S, deSilva HJ. Burden of infectious diseases in South Asia. BMJ 2004; 328: 811-5.

[18] Gentile A, Bhutta Z, Bravo L, et al. Pediatric disease burden and vaccination recommendations: understanding local differences. Int J Infect Dis 2010; 14: e649-e658.

[19] Onwujekwe O, Hanson K, Uzochukwu B. Examining inequalities in the incidence of catastrophic health expenditures on different healthcare services and health facilities in Nigeria. PLoS one 2012; 7 (7): e40811 doi: 10.1371/journal.pone.0040811.

[20] Lawanson A O, Olaniyan O. Health expenditure and health status in Northern and southern Nigeria: A comparative analysis using National Health account framework. Afr J $\begin{array}{llll}\text { Health } & \text { Econ 2013; } & \text { 31-46 }\end{array}$ http://doi.org/10.35202/AJHE.2013.2103. 